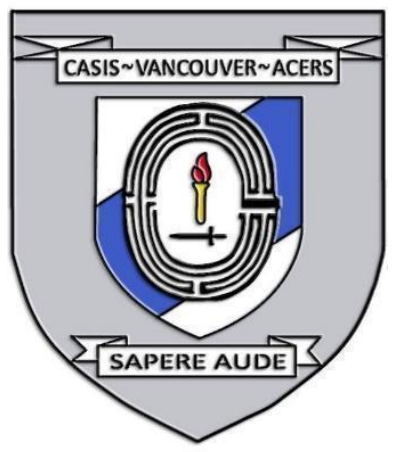

\title{
POLICING DURING COVID-19: PERSPECTIVES FROM THE MET POLICE, UK
}

Date: November 26th, 2020

Disclaimer: This briefing note contains the encapsulation of views presented by the speaker and does not exclusively represent the views of the Canadian Association for Security and Intelligence Studies.

\section{KEY EVENTS}

On November 26th, 2020, Deputy Assistant Commissioner Lucy D'Orsi presented Policing During COVID-19: Perspectives from MET Police, UK at the 2020 CASIS West Coast Security Conference. The presentation was followed by a panel question and answer period with other speakers. The key points of discussion focused on the challenges faced by MET Police in a saturated online environment, harvesting the right information, sharing it with the public and private sectors, and building trust.

\section{NATURE OF DISCUSSION}

\section{Presentation}

Deputy Assistant Commissioner D'Orsi centered her presentation on the MET Police "dare to share" program and how sharing the right information with the public and partners can improve overall trust and public safety. The presentation was contextualized in the COVID-19 era, the challenges the pandemic presented to the MET Police, and what measures were adopted to mitigate them.

\section{BACKGROUND}

\section{Presentation}

Policing in an era of data and information abundance requires partnerships to enhance the relations between the public, the private sector, and communities. These relationships are critical to the fight against terrorism and therefore, a "dare to share" approach is vital. However, when considering the saturation of information in the online sphere, a key challenge becomes ensuring the right 
message about rumors, conspiracy theories, and dangerous voices is heard. Further, it is necessary to ensure the public supports MET Police's work and how information and data is used; thus, building public trust is essential.

2020 has been a challenging year, to say the least. COVID-19 has had an enormous impact: it changed people's way of life, placed them in lock down, working from home, homeschooling, and endless Zoom calls. Counterterrorism policing is partly as it was before, but it is also demanding more creative solutions. The terrorist threat has adapted and continues its endeavours in the ongoing stress against the public in publicly accessible locations.

The MET Police have identified key areas for improvement regarding the information rich era society currently lives in: a) optimize data usage to detect and prepare for terrorist threats; and b) optimize data sharing to support risk management. For this, MET Police is in collaboration with the technology industry to develop artificial intelligence that will help understand unusual or anomalous behavior in public spaces.

A negative effect observed with lockdown measures, specifically closing schools and cancellation of medical appointments, was a significant decline in referrals to the PREVENT Programme. Consequently, there was a decrease in engagement and protective practices from strategic partners, which combined with people spending more time online resulted in an increase in extremists exploiting fears, anxiety, hate, grievances, and conspiracy theories, increasing the risk of radicalization. This gap is being filled by the "dare to share" program thousands of organizations are registered with MET Police free e-learning platform. Over 40,000 individual members of the public have also accessed it and 7,800 organizations are using it.

Although more information is being shared in a more coordinated and efficient manner as well as positive feedback for the "dare to share" program, one message remains consistent: more information is wanted - more information allows better understanding of threats and risks, and informed decisions. Based on feedback from the "dare to share" program, the next steps are to enhance digital capabilities - to increase its reach — to train and advise users. Moreover, it will continue to adapt and evolve, as well as push boundaries in innovative ways.

The Journal of Intelligence, Conflict, and Warfare 


\section{KEY POINTS OF DISCUSSION}

\section{Presentation}

- This era is arguably dominated by data and information; partnerships between public, private sector, and communities seems to be critical in the fight against terrorism.

- A key challenge is likely ensuring the right message is heard about rumors, conspiracy theories, and dangerous voices.

- Building trust has reportedly become ever more vital in the effort to keep the public safe.

- Harnessing vast amounts of data appears to be a crucial challenge, and law enforcement appears to be seeing the digital service with terrorism policing being used in almost every investigation.

- Key learning areas: better use of data and better sharing data with others to allow for risk management - e.g., collaborate with potential artificial intelligence developers to assist in understanding unusual or anomalous behavior in public spaces.

- Keeping up with threats does not appear to be enough. There seems to be a need to be ahead of them. Be innovative and push the boundaries. Working together by sharing as much information as possible and remaining updated in this digital age have been suggested as the most effective way to keep communities safe.

\section{cc) (i) $(9)$}

EY NC ND This work is licensed under a Creative Commons Attribution-

NonCommercial-NoDerivatives 4.0 International License.

(C) (Lucy D’Orsi, 2021)

Published by the Journal of Intelligence, Conflict, and Warfare and Simon Fraser University

Available from: https://jicw.org/

The Journal of Intelligence, Conflict, and Warfare 